\title{
Using a Collaborative Design Model for Developing Quality Online Courses
}

\section{Caitlin A. Keller, Worcester Polytechnic Institute}

Caitlin Keller is the Instructional Designer for Worcester Polytechnic Institute. Her primary role involves partnering with teaching faculty to create and develop courses in the online, blended, and face-to-face environments. Caitlin serves as the designer, facilitator, and instructional design consultant for the Faculty Institute for Online Teaching program. Caitlin holds a Master of Science degree in Learning Technologies and Instructional Design from Drexel University and a Bachelor of Science degree in Chemistry from Lebanon Valley College. 


\section{Using a Collaborative Design Model for Developing Quality Online Courses}




\begin{abstract}
This work-in-progress paper addresses the development of effective design partnerships as a follow up to the initial success of a faculty development pilot program targeting quality design in online courses at Worcester Polytechnic Institute (WPI). As WPI began delivering online education fifteen years ago, the faculty have most typically approached course design autonomously with minimal background in pedagogical practices, particularly those geared towards effective online learning. The pilot program allowed for more formal training in online pedagogy, but there is still area for growth in the quality of course design. As the push for online educational opportunities continues to grow and the demand for quality increases, WPI has invested in instructional design resources to help develop online courses through a collaborative design model, moving away from instructors developing their courses autonomously and in seclusion. Adopting a collaborative course design model requires a cultural shift for faculty in how they approach their course design and facilitation processes. Instructors who have participated in the quality design in online courses pilot program have been targeted to work one-on-one with an instructional designer to work in collaborative partnerships to make improvements to their existing courses or to design new courses. Data will be collected via surveys and interviews of faculty participants on their experiences, as well as observational data from the instructional designer and from evaluating courses based on a quality assurance rubric both before implementing changes and upon completion of an updated or new design. It is expected that implementing a mechanism for fostering strong partnerships between instructional designers and instructors will lead to higher quality online courses and will help the shift for future design processes to be more collaborative in nature. The added support could also have implications for higher adjunct faculty retention and higher student satisfaction. Ultimately, a more effective course design model will be formally introduced for faculty teaching online to best support the development of quality online courses at WPI. There are implications for this model to be adapted for use at other institutions in the future.
\end{abstract}

\title{
Introduction
}

Distance education enrollments within the higher education sector have shown continuous growth for 14 consecutive years [1]. Despite this trend, there is still uncertainty surrounding the quality of online programs that needs to be addressed [2]. Online education has now moved beyond the early adopters and become more mainstream, which is pushing more faculty to become involved with the design and delivery of online courses [3].

Ensuring high-quality online course design requires multiple areas of expertise that are not typically possessed by a single individual [4]. Collaboration among a team with instructional design expertise, technical knowledge, and subject matter knowledge is imperative for producing quality courses consistently [5]. Faculty members are typically viewed as the subject matter expert, but do not necessarily possess the requisite knowledge in instructional design and educational technologies to develop and deliver quality online courses in solitude.

There is great variance in how course design is addressed across different institutions. An individual course design model provides faculty autonomy in determining the content, structure, appearance and format of the course [6]. A structure model still provides faculty autonomy for 
determining content, but uses templates and guidelines to inform structure, appearance, and format [6]. Collaborative course design allows faculty to drive decision-making with the incorporation of input and guidance from instructional designers and instructional technologists [6]. A standardized model is a collective course design process involving a subject matter expert, curriculum specialist, instructional designers, instructional technologists, and any other relevant support staff [6]. Figure 1 highlights aspects of course design considerations over the spectrum of the types of models most prevalent in higher education institutions.

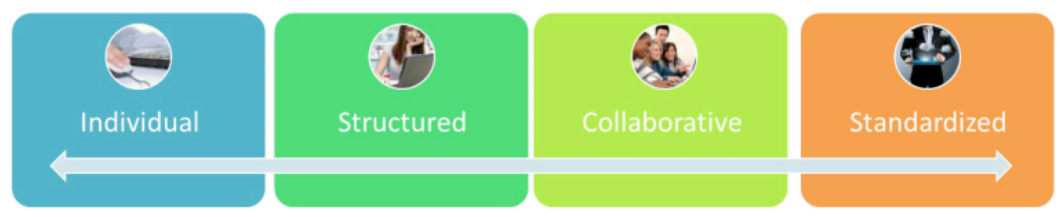

\begin{tabular}{|l|l|l|}
\hline $\begin{array}{l}\text { Resources allocated to } \\
\text { faculty }\end{array}$ & $\begin{array}{l}\text { Resources allocated to } \\
\text { courses }\end{array}$ \\
\hline $\begin{array}{l}\text { Governance in } \\
\text { departments }\end{array}$ & $\begin{array}{l}\text { Governance in centralized } \\
\text { online learning } \\
\text { department }\end{array}$ \\
\hline $\begin{array}{l}\text { Course development } \\
\text { autonomous process }\end{array}$ & $\begin{array}{l}\text { Course development a } \\
\text { standardized process }\end{array}$ \\
\hline $\begin{array}{l}\text { Combined roles for } \\
\text { course development and } \\
\text { instruction }\end{array}$ & $\begin{array}{l}\text { Separated roles for course } \\
\text { development and } \\
\text { instruction }\end{array}$ \\
\hline $\begin{array}{l}\text { Course revision process } \\
\text { flexible }\end{array}$ & $\begin{array}{l}\text { Course revision process } \\
\text { fixed }\end{array}$ \\
\hline
\end{tabular}

Figure 1. Types of course design models [6]

Many instructional designers in higher education advocate the use of a collaborative course design model for the development of quality online courses [3] - [5], [7]. More effective online courses that leverage technology efficiently can be created through faculty and instructional designers working together [7]. However, many factors influence the effectiveness of collaboration on quality course design. In particular, the literature repeatedly acknowledges the need for developing a strong working relationship built on mutual trust as the foundation for effective course design [3], [4], [8], [9]. It is recommended that relationship building is considered a crucial aspect in the early stages of the design process, thus establishing a common goal and better clarification on the roles and responsibilities of individuals [9]. If a course redesign only requires minor revisions, task-oriented collaboration is prominent and less focus is spent on relationship building as compared with course design projects involving new courses or courses requiring major revisions [4]. The foundation of a strong relationship can help with avoiding or minimizing conflict, as well as resolution when conflicts do arise [9], [10]. In addition, developing a shared vision involves creating shared images of the future that foster genuine commitment to the project instead of simply compliance [11].

As discussed by Parsloe and Leedham [11], members of a learning organization will recognize and accept the need to move toward higher levels of performance. Continuous learning is a crucial aspect for fueling improvements and the role of a coach-mentor helps to maintain focus 
on the learning opportunities and benefits [11]. By allowing the instructional designer to serve as a coach-mentor, faculty members are put into a position of learning that will lead to the development of higher quality courses.

Many higher education institutions are utilizing vetted tools to assess the quality of their course offerings. The Online Learning Consortium (OLC) has compiled a collection of assessment tools known as the OLC Quality Scorecards. The scorecards are used for evaluating various aspects of online education, including course design [12]. These resources are available at no cost, and OLC members also have access to interactive versions and are eligible for a more formal institutional review and endorsement process. Another popular option for assessing course design are the Course Design Rubric Standards developed by Quality Matters [13]. Access to the Quality Matters resources requires membership. Other tools have been developed on a smaller scale for use at specific institutions, such as the Online Course Assessment Tool developed by Western Carolina University for use with their Coulter Faculty Center eLearning Faculty Fellows as a means for providing constructive feedback and informing instructional improvement [14].

\section{Background}

Worcester Polytechnic Institute began offering videotape-based distance education in 1980 and moved to web-based online education in 2001. In the early adopter stages of online learning, WPI employed an individual course design model where faculty were autonomous in creating and adapting courses for online delivery. The growth in online education is forcing WPI, as well as many other institutions, to place more emphasis on quality course design in order to stay competitive and provide students with an effective learning experience.

In 2015, a training workshop was implemented using the service of external instructional design consultants. This workshop ran with two cohorts of early adopters of online teaching, and laid the groundwork for addressing the growing need for higher quality design. While access to an external instructional designer was included, faculty were not required to undergo extensive course development in order to complete the workshop. Initial feedback was very positive and helped in the advocacy for the acquisition of internal instructional design resources.

During the spring of 2016, the workshop was adapted to better meet the specific needs of WPI faculty and was facilitated internally by university staff. A full-time instructional designer was hired in summer 2016 and immediately began working with the spring 2016 faculty participants who had not yet completed consultation hours. Within this paper, the spring 2016 cohort is the first one included for data collection.

With the acquisition of a full-time instructional designer, WPI has begun to move toward a collaborative course design model. The initial workshop was redeveloped by the instructional designer and is meant provide more formal training in online pedagogy and develop partnerships between faculty members and the instructional designer. Participants in the new training program, which is now known as the Faculty Institute for Online Teaching, or FIOT, were targeted to work one-on-one with an instructional designer to create or redesign a course to better align with quality standards. 
A single phase of FIOT is being examined to determine the effectiveness of using a collaborative model rather than an individual model of course design on the quality of online courses. Data was collected via surveys and follow-up semi-structured interviews of faculty participants, meeting logs and observational reflections from the instructional designer, course evaluations provided by students, and course quality reviews conducted by online learning managers.

Preliminary results indicate that establishing collaborative partnerships between faculty members and instructional designers allows for the development of higher quality online courses. Additionally, stronger relationships between the design team have extended beyond the initial course design project, allowing for continued revisions for further improvement of the courses and the undertaking of new design projects. It is expected that establishing a well-defined collaborative course design model to be rolled out at the university will help to increase online course quality.

\section{Overview of the Faculty Institute for Online Teaching}

The faculty participants voluntarily enroll in the Faculty Institute for Online Teaching and receive a $\$ 1500$ stipend for successful completion. The stipend serves as an incentive for engaging faculty in increasing the quality of their online course offerings. Currently WPI faculty are not required to teach online courses, allowing the program to remain voluntary for the foreseeable future. Faculty scheduled to teach online in upcoming terms or those who are already teaching online are given preference for participation. Others are invited to participate if space is available, with cohorts not exceeding 20 participants. Participants come from a wide range of disciplinary backgrounds and have varying levels of expertise in online teaching. There is also a mix of tenured faculty, full-time tenure-track or non-tenured faculty, and adjunct faculty. WPI primarily offers online courses at the graduate level as part of the Corporate and Professional Education programs. Some summer courses are offered online at the undergraduate level at the discretion of the faculty instructor. Online summer undergraduate offerings are often paired with an in-person section of the course.

The Faculty Institute for Online Teaching program is delivered in three phases with a cohort of up to 20 faculty participants. First, participants attend an in-person 4-hour workshop focused on the foundational concepts of instructional design and introducing backward design as the primary process to utilize in course design. In phase II, participants are engaged in a 4-week asynchronous online course that begins to address backward design as it relates to each individual's course and allows participants to experience online learning from a student perspective. Participants work with various instructional materials to gain foundational knowledge and are required to engage in peer discussions to help explore pedagogical ideas and strategies. Each week, participants submit assignments that are meant to serve as working drafts for later refinement in the course design process. These assignments include defining course learning outcomes, mapping out and aligning formative and summative assessments, creating an assessment, creating a syllabus, and identifying possible strategies for engaging students in the online learning environments. Feedback is provided on each assignment submission promptly and participants are encouraged to begin outlining revisions. Phase III involves one-on-one consultations with an instructional designer and engaging in the course design process. Each 
participant is guaranteed at least ten hours of individual consultation time focusing primarily on pedagogy. Participants are only required to complete an initial 1-on-1 formal consultation meeting, typically lasting 30 minutes to one hour. Follow-up formal consultation meetings are encouraged, but are left up to the discretion of the faculty member. Training on technology and support outside of course design are not included in the allotted time with an instructional designer, but are also provided as needed by either the instructional designer or another member of the Technology for Teaching and Learning team.

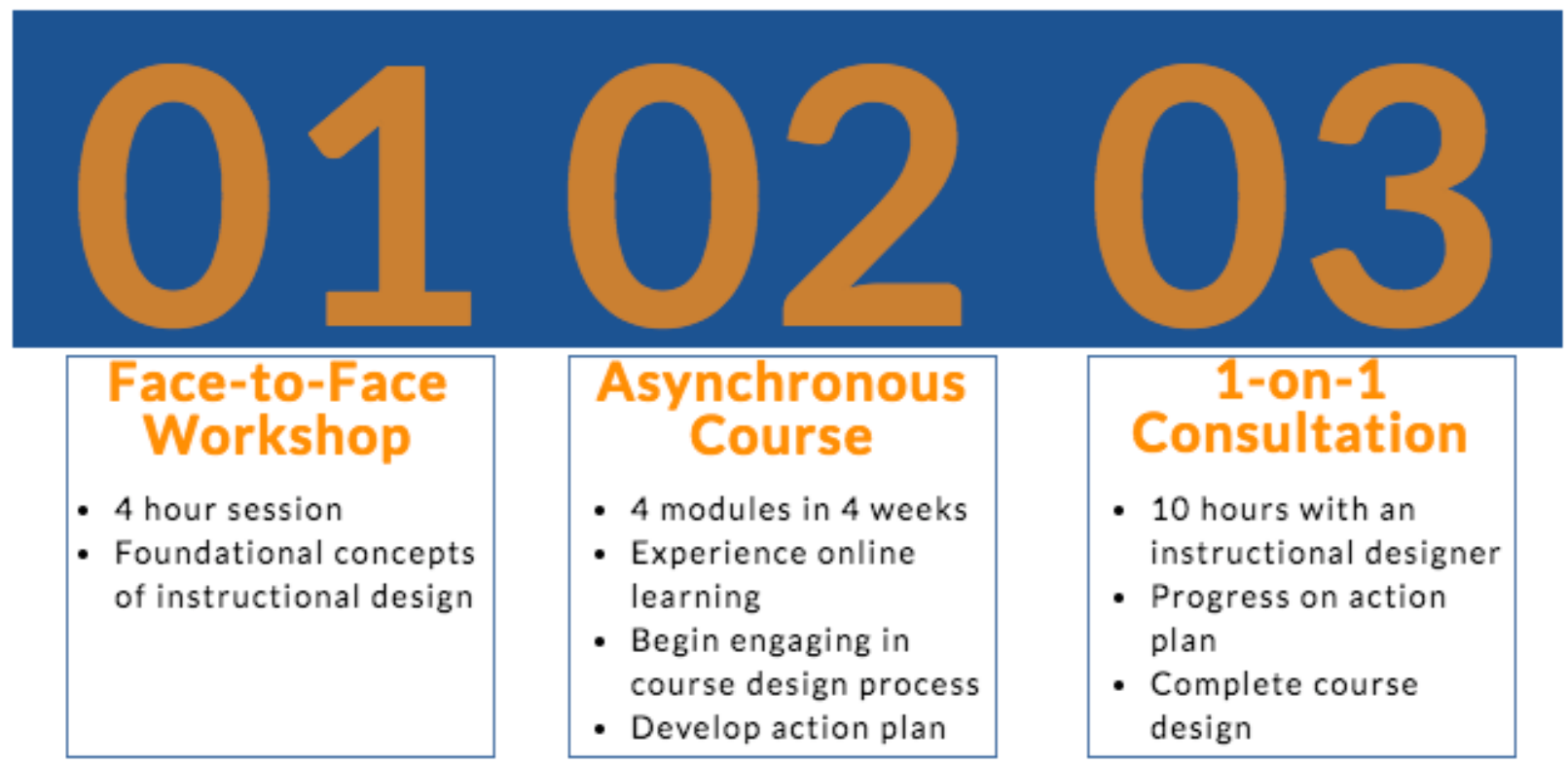

Figure 2. Overview of the Faculty Institute for Online Teaching

The instructional designer is actively present and engaging with the participants throughout all three phases. She serves as the main facilitator of Phases I and II, which allows her to engage with the whole cohort through discussions. She also provides feedback on each assignment submission during Phase II and has more in-depth discussions with individuals pertaining to their assignments as needed. By the time participants are starting Phase III, it is expected that they have established some familiarity with the instructional designer and can begin to strengthen the partnership. Participants are considered finished when they have created or redesigned a course that is reviewed by the online learning manager and deemed to be of acceptable quality.

At the time of writing, the Faculty Institute for Online Teaching has been run with four full cohorts of ten or more participants. Two smaller cohorts of five to seven participants who were remote and attended a synchronous virtual session for Phase I instead of a face-to-face session were also piloted. In total, 63 faculty have engaged with at least one phase of the program with $80 \%$ of participants completing all three phases. Approximately 4 participants are still on track for completion but have been delayed based on a variety of external factors.

\begin{tabular}{|l|c|c|c|}
\hline & Phase I & Phase II & Phase III \\
\hline Participants Completed & 63 & $56^{*}$ & $51^{*}$ \\
\hline
\end{tabular}

*Some participants are still in progress as of April 2018

Table 1. Participant Completion Values 


\section{Methodology}

The research involved examining data pertaining to quality course design and delivery from multiple perspectives. Faculty participants were encouraged to share insights and feedback through an anonymous survey. Willing participants were also interviewed to provide a more indepth understanding of their perceptions and experiences in the course design process. The instructional designer maintained meeting logs that identifies topics discussed and action items assigned and taken, as well as written observations and reflections on consultation meetings. Students in all online courses offered by WPI through the Corporate and Professional Education programs were asked to complete a survey in order to gain insight into their perception of the quality of the course and to provide feedback on their learning experience. In addition, course quality reviews were performed by online learning managers. Course quality reviews are based on a best practices checklist that is provided to faculty members prior to engaging in the design process. The reviews provide an internal quality score and faculty members are given written feedback on the quality of their courses to drive future improvements.

\section{Results}

Of the 51 participants who have fully completed the FIOT program, 12 responded to the survey. This accounts for $25 \%$ of the participants, offering a small sample size. However, their responses can be used to gain some insight on the faculty experience in engaging in collaborative course design processes.

When asked, "what resources did you utilize while working with an instructional designer (check all that apply)", the most common answer was receiving feedback on Canvas site organization of materials with $14 \%$ of respondents selecting this option. Respondents also commonly identified that discussions on pedagogical strategies, feedback on their course syllabus, and development of course materials were utilized. Associated written comments primarily focused on the usefulness of the 1-on-1 time with an instructional designer for having more focused discussions about courses, particularly regarding insight and advice on pedagogical strategies and tools, as well as receiving targeted feedback on course materials. 


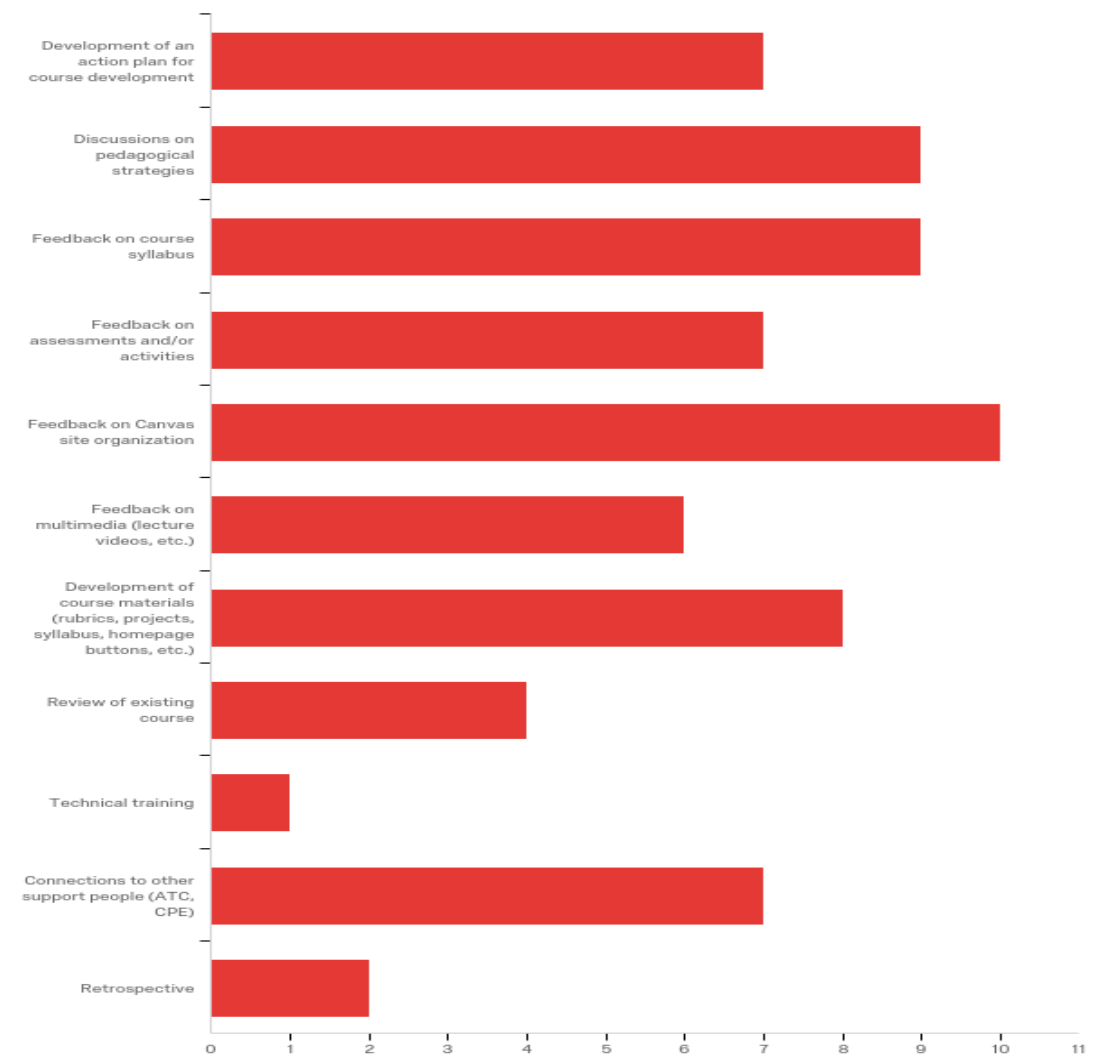

Figure 3. Results for "What resources did you utilize while working with an instructional designer (check all that apply)"

Respondents were also asked to comment on what other support the instructional design team could provide that would be beneficial to the course design and development processes. There were no common trends identified, showing that each instructor has specific needs that would need to be addressed individually. However, multiple responses involved the need for more technical training on varying tools. While this currently doesn't fall under the responsibilities of instructional design, it is a key insight to make sure faculty are getting enough support in their course development.

There was an even split in responses when asked "would you prefer mandatory scheduling of 1on-1 consultation time with an instructional designer?" The corresponding written comments highlighted the differences in how individuals were approaching their course design process, with some seeing the value in regularly scheduled time with action items and deadlines, while others felt they did not need intensive contact hours or project management mechanisms as they worked on their course development. This lack of desire to engage in consultation hours may be indicative of some faculty wishing to maintain the autonomous design practices they have been implementing for many years.

All respondents indicated that they would continue to utilize instructional design resources for the creation or redesign of other courses that they teach. The written comments expressed the value of having access to an instructional designer in designing and developing courses and a 
general belief that partnership with an instructional designer is valuable and is leading to improved course design.

Informal discussions about instructional design partnerships occurred with 22 participants. In addition, 5 participants volunteered to engage in semi-structured interviews as part of a retrospective process upon the conclusion of their new or redesigned course's first implementation. These conversations, both informal and semi-structured, provided qualitative information about the course design model pertaining to faculty perceptions.

For faculty members who had never taught online before, a major theme that emerged from discussions was that working with an instructional designer provided a safety net where aspects of the course could be discussed and reviewed before implementation with students. It also helped to connect them with valuable campus resources, such as instructional technologists and media specialists, that they were unaware of prior to consultation.

More experienced faculty members commented on how working with an instructional designer validated many strategies they were already implementing, as well as providing an opportunity to explore new strategies and make improvements. In particular, a participant commented that, "having somebody who was not closely involved with the course and could take on a different perspective was extremely useful to point out areas of improvement."

When asked about what they believed was necessary for a successful design partnership, a central theme was trust and mutual understanding. One participant stated, "In a lot of ways, my courses feel like my babies. To let someone else become involved with that relationship requires trust. The person needs to understand and respect my methods of teaching, and be willing to build from that foundation." Others also commented on the importance of working with someone that they "clicked" with who shared their vision for course development.

Out of 51 participants who completed the FIOT program, 26 utilized five or more sessions of formal one-on-one consultations with an instructional designer. Formal consultations lasted anywhere from 30 minutes to three hours. Every participant engaged in at least one formal consultation, with 31 participants requesting at least one follow-up consultation meeting after the required initial meeting. Outside of formal consultation, $77 \%$ of participants reached out informally for instructional design support via email, phone calls, or unscheduled discussions about their course.

\begin{tabular}{|l|c|c|c|}
\hline & No follow-up & 1-4 follow-ups & 5+ follow-up \\
\hline Number of participants & 20 & 5 & 26 \\
\hline Percentage of participants & $39 \%$ & $10 \%$ & $51 \%$ \\
\hline
\end{tabular}

Table 2. Participant engagement in follow-up formal consultation meetings

As the instructional designer had been active within Phases I and II of the FIOT workshop, she already had a basic understanding of each faculty member's course prior to an initial one-on-one consultation. Initial formal consultations were structured to allow the faculty member to provide more detailed insight into their course and their vision for the course creation or redesign. The 
majority of initial consultations also involved the development of an action plan, including the delegation of responsibilities where possible.

Reflections primarily revolved around themes consistent with the insights gathered from faculty members. Most consultation hours were spent discussing strategies, providing suggestions, and giving feedback on specific course materials. Faculty who sought out multiple follow-up meetings were more likely to ask for in-depth feedback on their course materials and organization. Those who did not engage in follow-up consultations tended to be more focused on clarifying the expectations and steps needed for completion of the FIOT, rather than on discussions about the course itself.

Consultations with faculty entirely new to either online teaching in general or to WPI were longer in length and covered much broader topics. These discussions were often dominated by the expectations WPI holds for course materials and delivery and on how to incorporate identified best practices. Online teaching veterans tended to come to consultation meetings with very specific questions and were often looking for more focused advice or feedback.

Veterans and new faculty were equally as likely to request formal follow-up consultation meetings, as well as engage in informal communication via email, phone calls, or unscheduled discussions.

In informal quality review processes, faculty members who engaged more frequently with the instructional designer, both formally and informally, were more likely to produce higher-quality courses that were better organized within Canvas and included more student opportunities for interaction and collaboration with one another and with the instructor. In addition, these highly engaged faculty members were more willing to discuss their own reflections on their teaching practices and share their student survey data with the instructional designer to drive discussion for further course improvement.

Course quality reviews were performed by online learning managers with the permission of faculty members. For the 2016-2017 academic year, the average quality review score for FIOT participants was 3.7 on a 4.0 -point scale. Courses created by faculty members that did not participate in FIOT have an average score of 3.1, showing a 16\% increase in quality. Early data from the 2017-2018 academic year are showing similar quality scores for FIOT participants.

Within the standard end-of-course survey, online students were asked, "my overall rating of the quality of this course is..." and answers were recorded on a 5-point scale. For courses taught by FIOT participants, there was a minimal increase in reported quality from the student perspective. These results are inconclusive for identifying student perception on the quality of their online course experiences.

\section{Future Considerations}

The faculty survey and discussions with faculty participants provided high levels of perceived value for engaging in a design partnership with an instructional designer. Faculty frequently mentioned that feedback on course materials and discussions on pedagogical strategies that led to 
improvement in course design were useful. The willingness to openly receive constructive criticism from an outside perspective via the instructional designer highlights the security faculty members felt within the partnership. Statements in interviews also verified this, with faculty members mentioning the importance of trust and understanding within the partnership.

However, there is still a population of participants who are not engaged in an extended partnership despite the available opportunity. There are many possible variables that may have led to this outcome. Based on the literature and data collected from this pilot study, it is likely that a focus on developing the relationship early in the process, as well as mutual trust and understanding between the faculty member and the instructional designer would have helped the development of stronger design partnerships. Taking the time to define specific roles and responsibilities early in the partnership, preferably in the initial one-on-one consultation, can be a crucial step in creating a mutual understanding between members.

There is also huge variance on the timeline for faculty participants between when they are engaged in the course design process and when their course may be offered. This could have an influence on the engagement level of the faculty member in the collaborative design model. If they have a very short timeline to develop a course, they will not have the bandwidth to engage in more consultation. When the course is not being offered in the foreseeable future, it could decrease motivation for extensive partnership in the course design process at the time of participation in the FIOT program.

In the current model, it is left up to faculty to schedule follow-up consultations or reach out for support. Splitting this responsibility allows the instructional designer to play a more active role in maintaining an extended partnership could increase the likelihood of engagement of the faculty members. As instructional design partnerships are quite new to WPI, taking a passive role initially allowed for the early adopters to buy-in into the process. Champions of the collaborative course design process are emerging and will serve as a conduit for recruiting new participants, as well as provide an extended support system for building a culture around quality online course design. Maintaining these partnerships will be crucial to the overall growth and success of quality design initiatives. The instructional designer can better connect to unsure faculty members by sharing the successes of these champions and openly discussing the factors that are causing their hesitancy.

Course quality reviews are showing positive results for participants of the FIOT program. They are also highlighting inconsistencies in quality design and where faculty may need more extensive support that can inform future development of faculty development efforts. The current course quality process is based on a best practices checklist that identifies common aspects of course design. A more extensive, vetted quality design rubric would be more useful for providing faculty with explicit feedback to inform improvement. Faculty are given access to the best practices checklist early into the process, but it is rarely discussed directly within the course design process. Focusing design and development efforts around well-defined standards could help to increase the quality of the product [11]. There are multiple quality rubrics available through professional organizations that could be utilized or adapted to address the specific needs of the institution [12], [13]. Starting with these rubrics that are already vetted by leaders in online education may help with acquiring buy-in from the faculty. Quality design is 
commonly addressed in consultation with the instructional designer, but a strong, vetted assessment tool would be a great resource for facilitating more explicit discussion surrounding the meaning of quality in course design and development.

Developing a culture around quality design that extends beyond partnership with the instructional designer to include the online learning managers and other support staff would also have a positive influence on overall quality course design. Faculty members may need more support in various areas that cannot be accomplished solely by the instructional designer. Having an extended support system that all share a common goal focused on quality would be beneficial [11]. More emphasis on retrospective meetings and follow-up participation in the design process for course iterations or new course designs would also be beneficial for veterans of the FIOT program. This encouragement can come from the instructional designer, as well as the online learning manager or other support staff who are assisting the faculty member.

Extensive analysis of students' written comments about the course would be needed to provide a deeper understanding of perceptions of quality from the student perspective. However, written comments are only provided directly to the faculty members, so accumulating sufficient data for this analysis is a challenge. It would also be insightful to develop focus groups to have a better understanding of what students, as consumers of online education, perceive as quality in their courses and how their experiences are aligned with those expectations.

\section{Conclusion}

This study provides a preliminary analysis of the effectiveness of using a collaborative course design process for increasing quality. Quality design has improved through the partnership of faculty members with an instructional designer. There are also implications that strong working relationships based on trust, mutual understanding of roles, and a common goal can have a positive impact on course design, including the continuation of the partnership for improvements to the course and the creation of new courses. Focus should be placed on the formation of these effective partnerships as part of the process in order to maximize the impact on quality design.

The implementation of vetted quality standards and assessment tools would be beneficial for establishing a common vision between the instructional designer and faculty member. Further research on student perceptions of quality within their courses could also provide valuable insight to inform the current gaps in quality for the university's online course offerings.

\section{References}

[1] J. E. Seaman, I. E. Allen and J. Seaman, "Grade increase: Tracking distance education in the United States," 2018. [Online]. Available: http://www.onlinelearningsurvey.com/highered.html. [Accessed: Jan. 10, 2018].

[2] M. Britto, C. Ford and J Wise, "Three institutions, three approaches, one goal: Addressing quality assurance in online learning," Journal of Asynchronous Learning Networks, vol. 17, no. 4, pp. 11-24, 2014. [Online]. Available: http://dx.doi.org/10.24059/olj.v17i4.402. [Accessed Jan. 4, 2018]. 
[3] B. Brown, S. E. Eaton, D. M. Jacobsen, S. Roy and S. Friesen, "Instructional design collaboration: A professional learning and growth experience," MERLOT Journal of Online Learning and Teaching, vol. 9, no. 3, pp. 439-452, Sept. 2013. [Online]. Available: http://jolt.merlot.org/vol9no3/brown_0913.htm. [Accessed Jan. 10, 2018].

[4] I. T. Chao, T. Saj and D. Hamilton, "Using collaborative course development to achieve online course quality standards," The International Review of Research in Open and Distributed Learning, vol. 11, no. 3, pp. 106-126, Oct. 2010. [Online]. Available: ERIC, https://eric.ed.gov/?id=EJ913863. [Accessed Jan. 22, 2018].

[5] D. G. Oblinger and B. L. Hawkins, "The myth about online course development," EDUCAUSE Review, vol. 41, no. 1, pp. 14-15, January/February 2006. [Online]. Available: https://er.educause.edu/articles/2006/1/the-myth-about-online-coursedevelopment. [Accessed Jan. 10, 2018].

[6] J. Mandernach, "Individualized models for integrating standardized course design," in New Directions in Instructional Design: Keeping Pace in a Time of Rapid Change, Apr. 20, 2017. [Online].

[7] R. Moore, "Working together: The public records webinar series," EDUCAUSE Review, Nov. 4, 2013. [Online]. Available: https://er.educause.edu/articles/2013/11/workingtogether-the-public-records-webinar-series. [Accessed Jan. 22, 2018].

[8] K. Campbell, R. A. Schwier and R. F. Kenny, "The critical, relational practice of instructional design in higher education: An emerging model of change agency," Educational Technology and Research Development, vol. 57, no. 5, pp. 645-663, Oct. 2009. [Online]. Available: http://www.jstor.org/stable/40388655. [Accessed: Dec. 5, 2017].

[9] E. Tate, "Quashing tension, boosting cooperation," Inside Higher Ed, May 10, 2017. [Online]. Available: https://www.insidehighered.com/digitallearning/article/2017/05/10/roundup-instructional-designers-and-faculty-ideas-working. [Accessed Jan. 17, 2018].

[10] E. Tate, "Easing instructional designer-faculty conflicts," Inside Higher Ed, May 3, 2017. [Online]. Available: https://www.insidehighered.com/digitallearning/article/2017/05/03/easing-conflicts-between-instructional-designers-and-faculty. [Accessed Jan. 17, 2018].

[11] E. Parsloe and M. Leedham, Coaching and Mentoring: Practical Conversations to Improve Learning, $2^{\text {nd }}$ ed. Philadelphia, PA: Kogan Page, 2009.

[12] Online Learning Consortium, "OLC quality scorecard - Improve the quality of online learning \& teaching." [Online]. Available: https://onlinelearningconsortium.org/consult/olc-quality-scorecard-suite/. [Accessed: Jan. 30, 2018].

[13] Quality Matters, "Higher ed rubric standards." [Online]. Available: https://www.qualitymatters.org/qa-resources/rubric-standards. [Accessed Jan. 30, 2018]

[14] Coulter Faculty Center, "Online course assessment tool (OCAT) and peer assessment process," Apr. 25, 2007. [Online]. Available: https://www.wcu.edu/WebFiles/PDFs/facultycenter_OCAT_v2.0_25apr07.pdf. [Accessed: July 15, 2017]. 